\title{
The influence of repeated loading on work of the steel fiber concrete drainage trays and pipes on the roads
}

\author{
Oleksandr Andriichuk ${ }^{1 *}$, Volodymyr Babich ${ }^{2}$, Ivan Yasyuk $^{1}$, and Serhii Uzhehov ${ }^{1}$ \\ ${ }^{1}$ Lutsk National Technical University, Civil Engineering Department, 43018 Lutsk, Lvivska St. 75, \\ Ukraine \\ ${ }^{2}$ National university of water management and nature resources use, Civil Engineering and \\ Engineering Structures Department, 33000 Rivne, Soborna St. 1, Ukraine
}

\begin{abstract}
The drainage system is one of the components of the road design. The condition of the subgrade and pavement depends on its effectiveness. The main structural elements of the drainage system on the roads are gutters and pipes. They are made of concrete or reinforced concrete. Under the influence of climatic factors and fluctuations of the vibration caused by the vehicles movement on the surface, it occurs destruction: formation of cracks, potholes, husking of concrete, destruction of protective layer of concrete, etc. It should be noted that these structures perceive the dynamic and thermal effects. The low fracture materials toughness poses the issue of searching ways of its increase. One solution of this problem is the use of dispersion-reinforced concrete gutters and pipes. The article presents the results of research strength, crack resistance and deformability of gutters and pipes using steel fiber reinforced concrete under the action of repeated loads
\end{abstract}

Non-pressure pipes and street gutters on the roads used in the construction of drainage systems for drainage of rain, snowmelt and groundwater from road sections with a high degree of load, highways, walkways, airports and terminals. It should be noted that future traffic on the roads I-A and I-B categories, according to calculations takes more than 10000 vehicles per day. The throughput of an individual vehicles of Ukraine even exceed these standards, in particular, the highway Kyiv-Boryspil traffic is about 40 thousand vehicles per day. A huge stream of traffic through the cross section of a road of this class creates significant dynamic vibration oscillations, which act on road transport facilities. While the low fracture toughness of the materials of gutters and pipes puts the issue of finding ways to improve it.

One solution in this direction is using of concrete in these construction of gutters and pipes with the addition of reinforcing elements looks like a short steel cuts - steel fiber reinforced concrete. The combination of rigid (and because of this with considerable reserves of strength) fibers with the matrix (concrete) allows to localize the danger associated with brittle destruction of the matrix and to realize the basic properties of fibers: greater potential tensile strength and high modulus of elasticity.

\footnotetext{
* Corresponding author: aleklutsk@gmail.com
} 
Application efficiency of steel fiber concrete in building structures is achieved by reducing labor costs for reinforcement works, combining technological operations of preparation, reinforcing, laying and compaction steel fiber reinforce concrete mixture, extending the life of structures and reducing costs for various types of maintenance. Use it instead of the concrete significantly reduces the consumption of construction while simultaneously improving operating properties, durability, temperature resistance, water resistance [1-3].

Despite a number of qualitative advantages, steel fiber reinforced concrete (SFRC) is still not fully investigated material. It should be noted that the relevance of using SFRC for the manufacture of the roadside gutters and pipes for wastewater are described in the article [4-5].

In research is established that steel fiber reinforced concrete as an effective material should be used for the manufacture of gutters and pipes of the drainage systems; the use of gutters and pipes from SFRC for water and wastewater instead of standard reinforced concrete is allows to: completely abandon the use of rebar; reduce the consumption of materials of construction, and as a consequence, their weight; to reduce labor costs for production of structures and significantly increase the durability of constructions. In other papers [6-8] presented the results of the researching of SFRC pipes and gutters to the action of a single load.

The article presents the results of empirical researches of strength and deformation characteristics, stress-strain state of non-pressure pipes and roadside gutters made of steel fiber reinforced concrete to the action of repeated short-term loads. These studies were conducted in the building laboratory of Lutsk NTU.

To perform the research was made several gutters and pipes. In the process of testing samples is compared concrete, reinforced concrete and SFRC samples.

For concreting pipes and gutters of type "Half-pipe" was designed and manufactured a special easily-dismountable metal formwork (Fig. 1). It provided the evenness of the surface of experimental samples with a wall thickness $t=40 \mathrm{~mm}$, an inner diameter $d_{i n}=300 \mathrm{~mm}\left(d_{\text {out }}=380 \mathrm{~mm}\right)$ and the length of the elements $l=300 \mathrm{~mm}$.
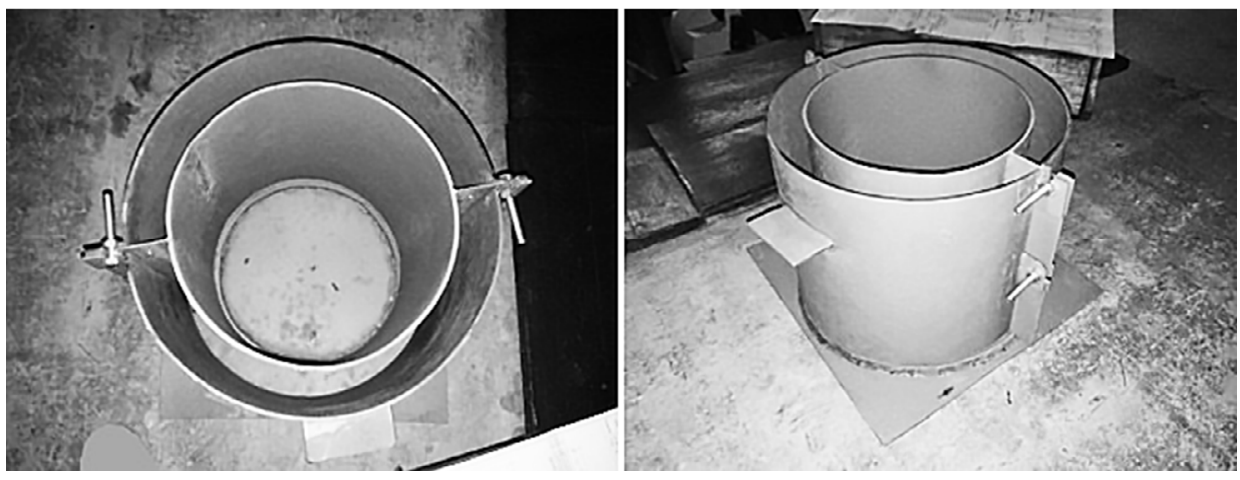

Fig. 1. General view of the formwork to producing test samples of gutters.

Wave fiber with a diameter of $0.8 \mathrm{~mm}$ and a length of $50 \mathrm{~mm}$ is applied to obtain steel fiber concrete as a particulate reinforcement of research gutters (Fig. 2).

Testing of prototypes is performed by using a metal traverse with concentrated load. The lower part of the element leaned on a rigid base. For this test will be used the hydraulic press PSU-125. To improve the measurement accuracy of the current effort is used an exemplary dynamometer, that allows to measure the loadings with an accuracy of $50 \mathrm{~N}$. In this case, the loading is created using hydraulic jack. Gutters researches are carried out according to the scheme presented on Fig. 4, and the researches of pipes on Fig. 5. 

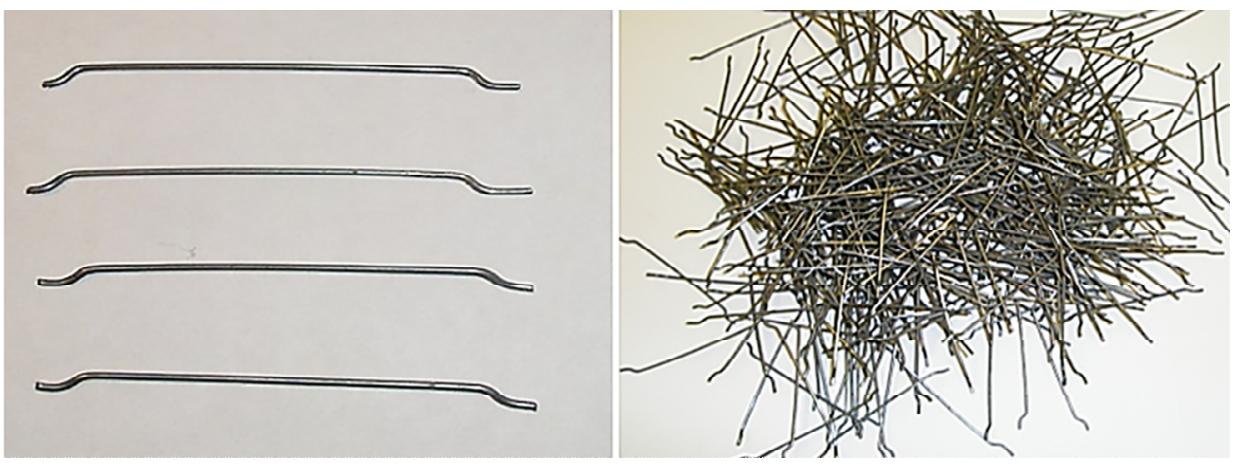

Fig. 2. General view of the steel anchor fibers for the manufacture of SFRC.

On Fig. 3 presented SFRC gutters and pipes after demolding.

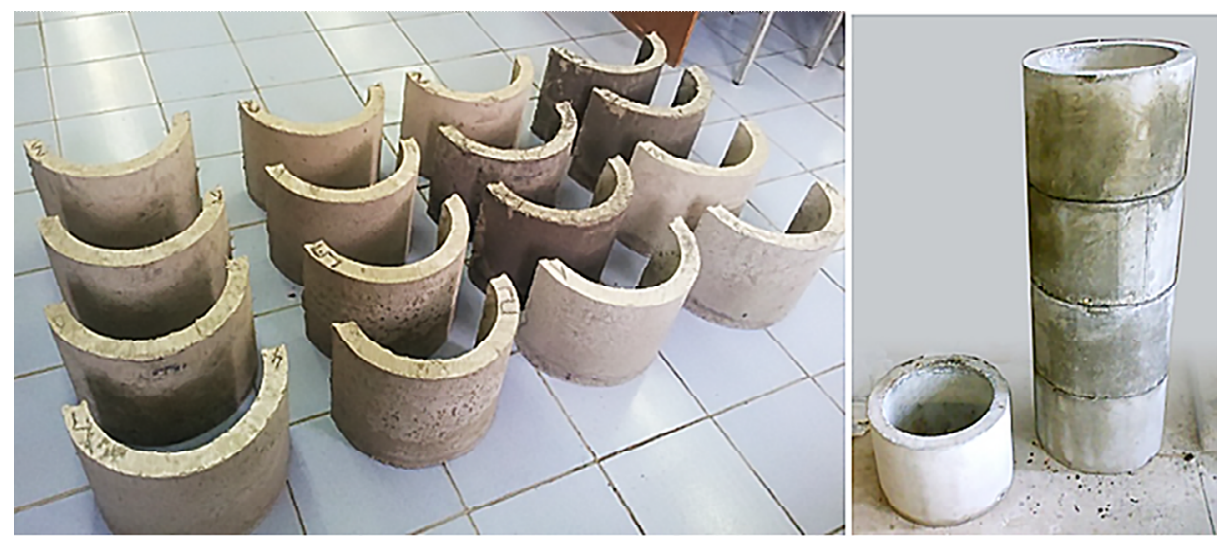

Fig. 3. General view of produced SFRC gutters and pipes.
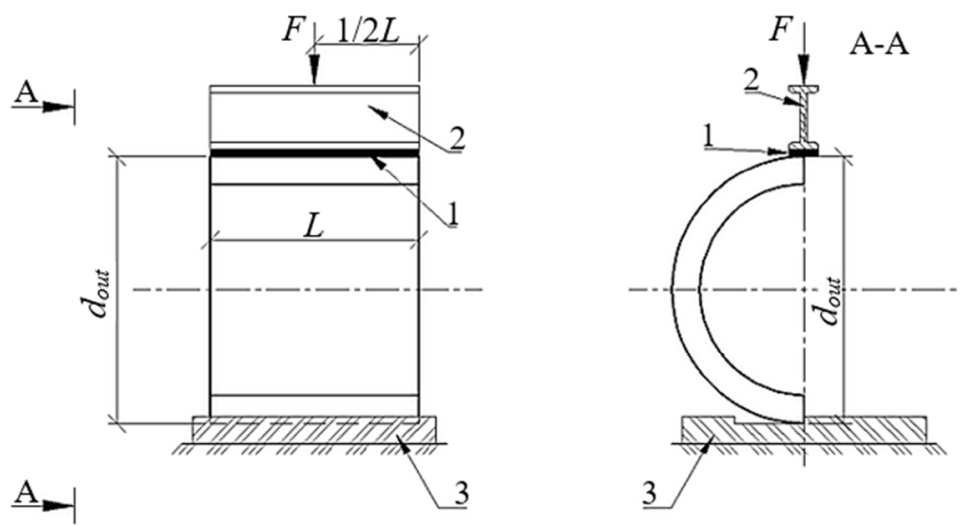

Fig. 4. Gutter's test scheme: 1 - rubber carpet; 2 - metal traverse; 3 - motionless basis.

During the research of gutters and pipes the loading is applied through the steps of 8 $12 \%$ of the breaking stress, that defines by the theoretical method during the calculation. After each stage of loading the pause is withstood for 5-7 minutes, in which the necessary data was taken (indicators measurements, strain indicators of the complex and measured crack widths $\left.\left(a_{c r c}\right)\right)$. 

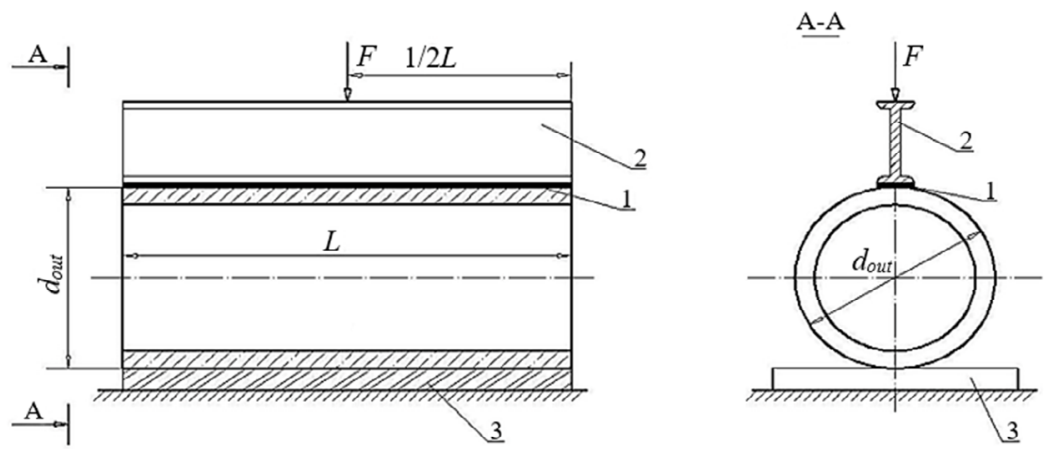

Fig. 5. Pipe's test scheme: 1 - rubber carpet or cement mortar; 2 - metal traverse; 3 - motionless basis.

For measuring displacement of the prototype walls that resulting from the appropriate loading of gutter, used the dial indicator MIG-1 with a scale division of $0.01 \mathrm{~mm}$, which is attached by using of metal holders, which in turn stick to the concrete surface with an epoxy glue. This ensures their reliable position relative to the sample during the measurement of the displacements of the gutter walls in the diametrical vertical direction.

Crack widths will be determined with a microscope MPB-3 with a scale division of $0.02 \mathrm{~mm}$. In order to improve the visual monitoring of the occurrence and growth of cracks, lime mortar is applied to inner and outer surfaces of elements before researches.

For measuring the strain of concrete and SFRC strain gauges with a working base of $50 \mathrm{~mm}$ are glued on the inner and outer surfaces of the pipes and gutters, whose data are recorded by tensometric measurement complex. General view of the test pipes and gutters is shown in Fig. 6 and Fig. 7.

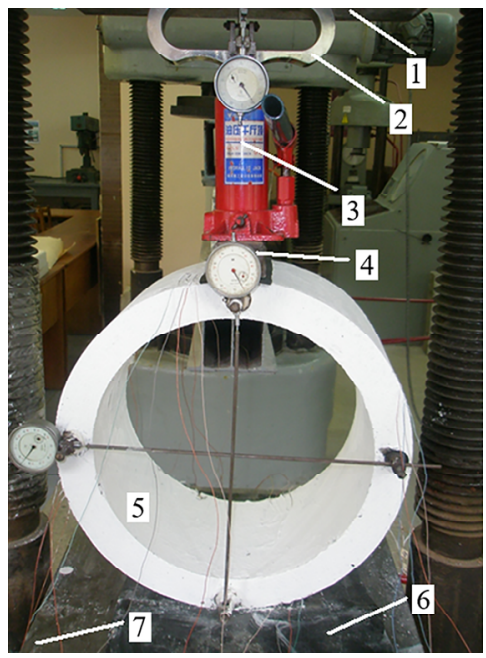

Fig. 6. General view of the test elements of annular cross-section (pipe): 1 - upper support press plate of PSU-125; 2 - testing dynamometer; 3 - hydraulic jack; 4 - metal traverse; 5 - test element of annular cross section; 6 - rubber carpet; 7 - lower support press plate of PSU-125.

A detailed description of the methodology of experimental research SFRC road drainage gutters presented in paper [9], and the methodology of research SFRC pipes presented in paper [10].

Researches of reinforced concrete gutters were carried out (labelling: $\mathrm{RCg}-1, \mathrm{RCg}-2$ and $\mathrm{RCg}-3$ ) with the percentage of reinforcement steel frames $\mu=2$. During the research, 
gutters $\mathrm{RCg}-1-3$ for 10 cycles were loading to level $\eta_{c y c}=0.6$ of the breaking stress, and at 11 th cycle were brought to destruction.

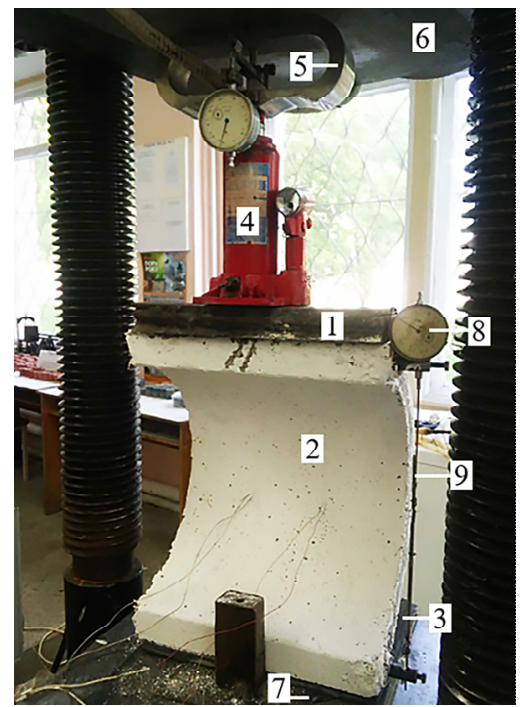

Fig. 7. General view of the drainage gutters research: 1 - metal traverse; 2 - research drainage gutter; 3 - motionless basis; 4 - hydraulic jack; 5 - testing dynamometer; 6 - upper press plate of PSU-125; 7 - lower press plate of PSU-125; 8 - displacement sensor; 9 - upright guides.

Deformation of the cross section gutters RCg-1-3 $(\Delta l)$ within $F=0-6.33 \mathrm{kN}$ occurred linearly and reached the maximum load on this section $(F=6.33 \mathrm{kN})$ value $\Delta l=0.94 \mathrm{~mm}$. Within $F=6.33-9.33 \mathrm{kN}$ deformation of reinforced-concrete gutters increased nonlinear to values $\Delta l=0.94-2.78 \mathrm{~mm}$ (the process of cracking). Further deformation of the samples got a specific linear pattern, but with a large increasing.

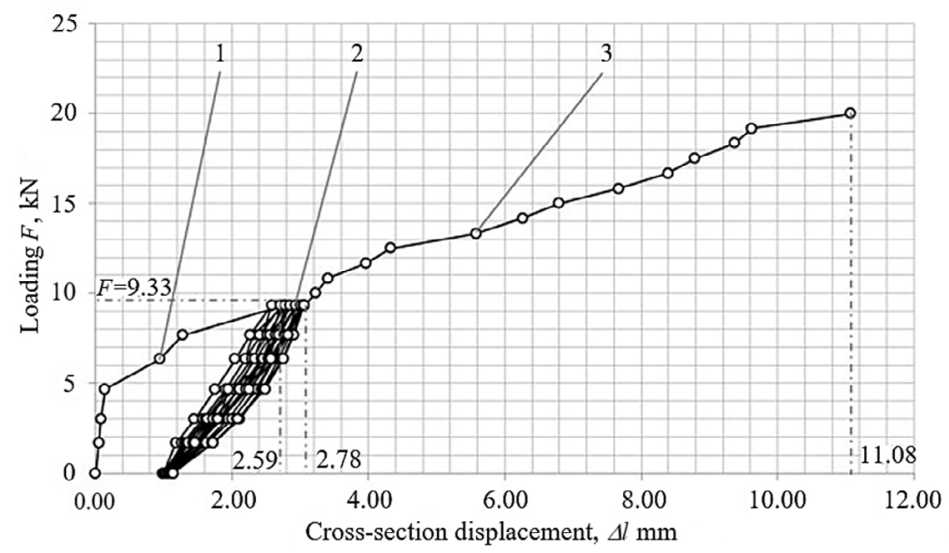

Fig. 8. Deformation of RCg gutters under the action of repeated loads: 1 - during the 1st cycle; 2 during the 2 nd-10th cycles; 3 - during the 11 th cycle.

The first visible cracks in the samples $\mathrm{RCg}-1-3$ occurred in the first cycle at the load $F=7.67 \mathrm{kN}\left(a_{c r c}=0.23 \mathrm{~mm}\right)$. At the maximum load in the first cycle, which was $F=9.33 \mathrm{kN}$, the cracks opened to the $a_{c r c}=0.38 \mathrm{~mm}$. At the unloading the samples to $F=0 \mathrm{kN}$ residual crack widths were within $a_{c r c}=0.28-0.43 \mathrm{~mm}$. Form of cracks in the RCg gutters is shown on Fig. 9. 
Researches of SFRC gutters were carried out (labelling: SFRCg-1, SFRCg-2 and SFRCg-3) with the percentage of fibers $\mu=2$. During the research gutters SFRCg-1-3 for 10 cycles were loading to level $\eta_{c y c}=0.6$ of the breaking stress, and at 11 th cycle were brought to destruction.
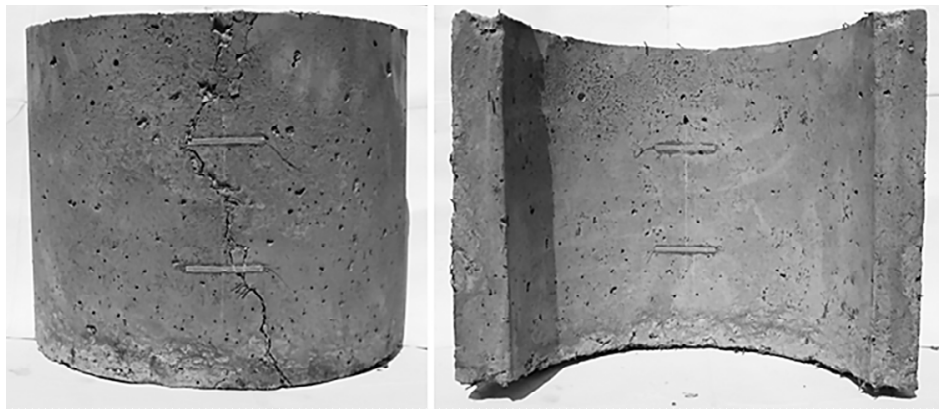

Fig. 9. The form of cracks in the RCg gutters: area of tension and compression.

At the loading on the cycles of maximum effort $(F=9.33 \mathrm{kN})$ with each cycle of SFRC$1 . .3$ samples deformation is constantly increasing in the interval $\Delta l=0.47-1.07 \mathrm{~mm}$ (Fig. 10).

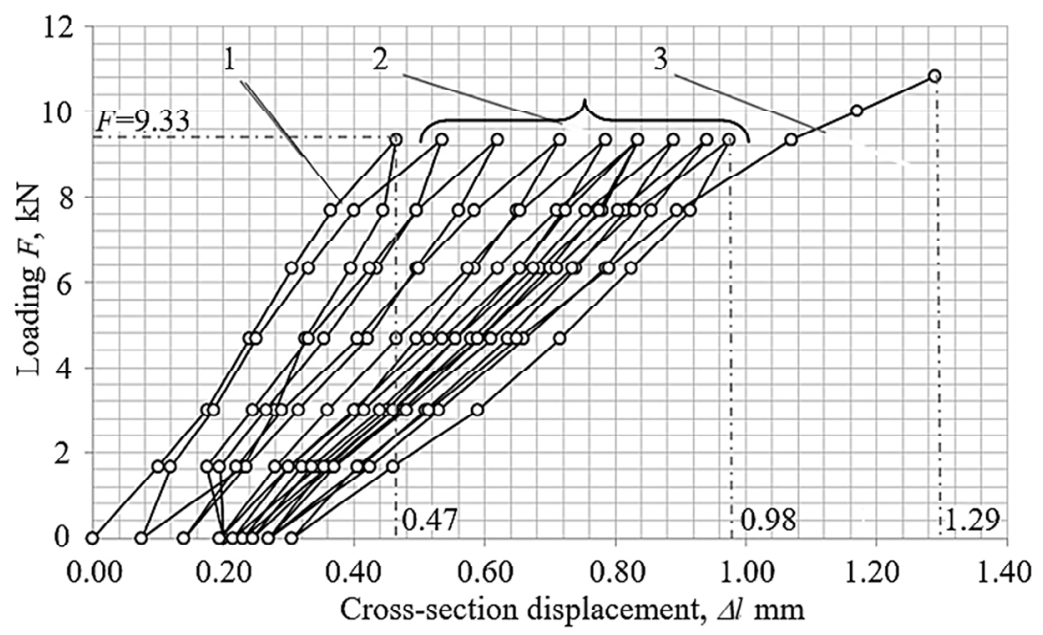

Fig. 10. Deformation of SFRCg gutters under the action of repeated loads: 1 - during the 1st cycle; 2 during the 2nd-10th cycles; 3 - during the 11 th cycle.

In the elements SFRC-1-3 the first visible cracks appeared at 10 cycle at $F=9.33 \mathrm{kN}$ and width $a_{c r c}=0.05 \mathrm{~mm}$. At the 11 th cycle at $F=9.33 \mathrm{kN}$, crack widths already were at $a_{c r c}=0.1 \mathrm{~mm}$. View of cracking of the SFRCg gutter (Fig. 11).

Studies of non-pressure pipes under the action of repeated loads was conducted on concrete samples (RCg-1, RCg-2 and RCg-3) and SFRC samples (SFRCg-1, SFRCg-2 and SFRCg-3). Elements were reinforced with steel frame (RC) and anchoring fibers (SFRC) with the percentage of reinforcement $\mu=2.5$.

The samples during ten cycles were loaded by degrees to the level $\eta_{c y c}=0.6$ from the breaking stress, and on the 11th cycle was brought to destruction. Unloading of samples on cycles were carried out the same steps as in the load. Cycles 4th, 6th and 8th were intermediate, another words, they were loaded once to its maximum value, to $F=7 \mathrm{kN}$, and then unloaded to $F=0 \mathrm{kN}$.

During the study, the pipes move sections of samples in vertical and horizontal directions were fixed, and the determined deformation of the concrete in a compressed and 
stretched areas using strain gauges with a base of $50 \mathrm{~mm}$, which were connected to straingauge station "Izmeritelnaya tenzometricheskaja sistema VNP-8".
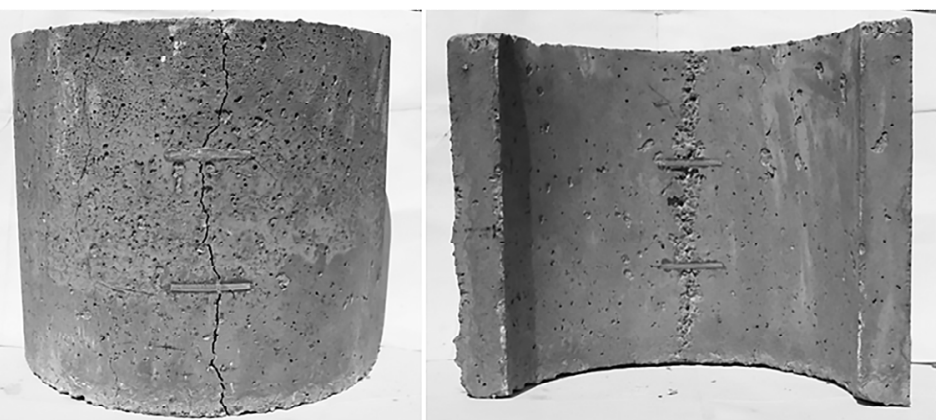

Fig. 11. The form of cracks in the SFRCg gutters: area of tension and compression.

Determined by using dial indicators, averaged displacement of the cross sections under the action of repeated loads in concrete samples ( $\mathrm{RCg}-1-3)$ are presented in Fig. 12, and in the SFRC samples (SFRCg-1-3) are presented in Fig. 13.

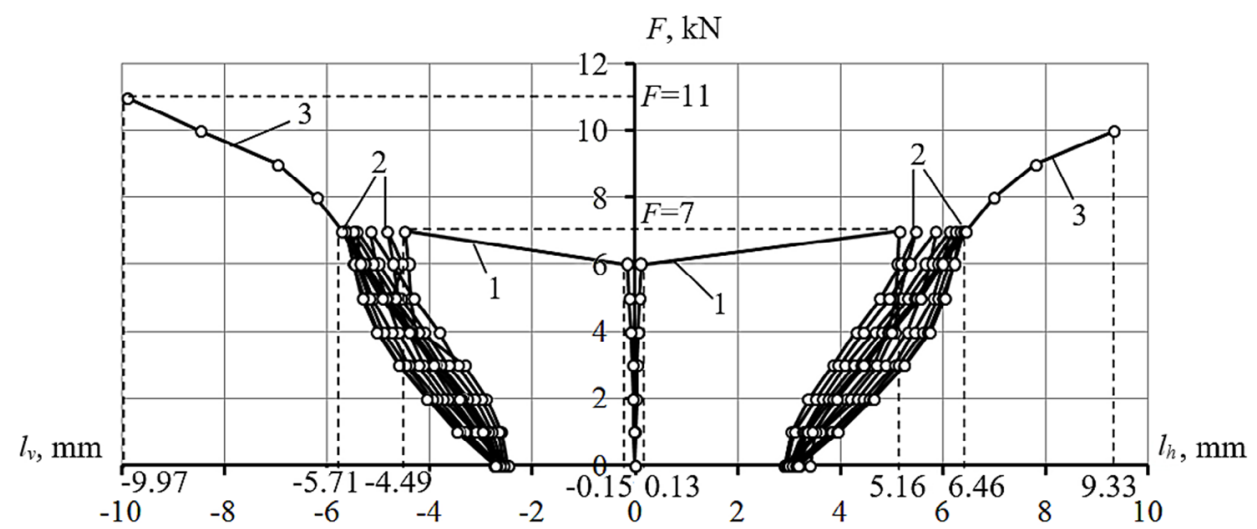

Fig. 12. Averaged displacement cross-sections of samples RCg-1-3 in horizontal $\left(\Delta l_{h}\right)$ and vertical $\left(\Delta l_{v}\right)$ directions: 1 - during the 1st cycle; 2 - during the 2nd-10th cycles; 3 - during the 11 th cycle.

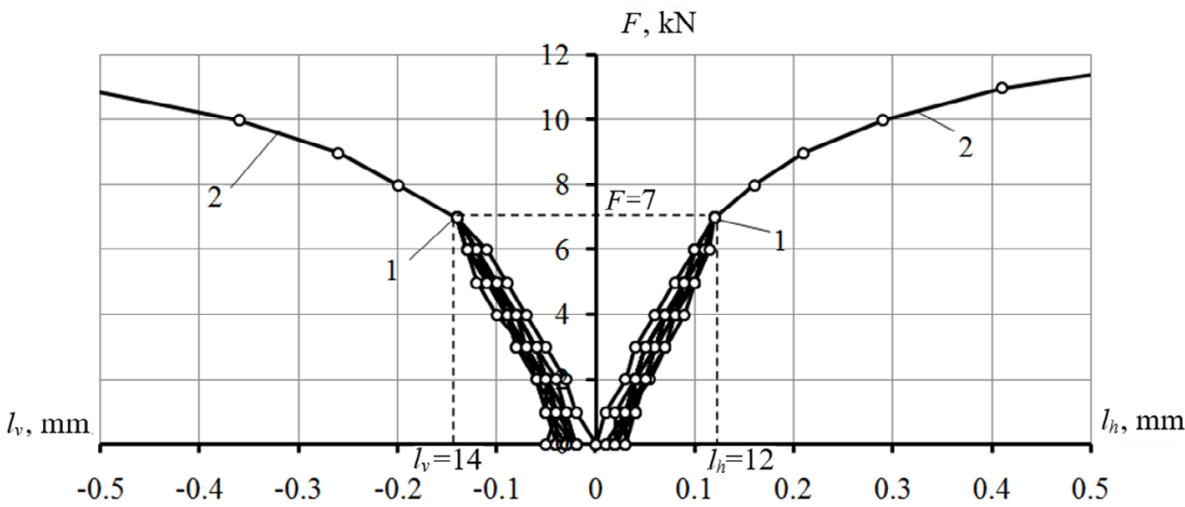

Fig. 13. Averaged displacement cross-sections of samples SFRCg-1-3 in horizontal $(\Delta l h)$ and vertical $\left(\Delta l_{v}\right)$ directions: 1 - during the 1st cycle; 2 - during the 2nd-10th cycles; 3 - during the 11 th cycle. 
Deformation of concrete in samples of $\mathrm{RCg}-1-3$ within $F=0 \div 6 \mathrm{kN}$ has developed almost linearly and reached a maximum value of $F=6 \mathrm{kN}, \mathcal{E}_{\max }=13 \times 10^{-5}$ (Fig. 14). During the initiation of the effort $F=7 \mathrm{kN}$ in the stretched areas of the elements $\mathrm{RCg}-1-3$ began to appear cracks. The cracking led to failure of the strain gauges that were placed in these areas, both outside and inside. Therefore, curve $F-\mathcal{E}$ in the area stretching ends with $F=6 \mathrm{kN}$. In the zone of compression when loading effort $F=7 \mathrm{kN}$ strain increased from $\mathcal{E}_{c}=13 \times 10^{-5}(F=6 \mathrm{kN})$ to values $\mathcal{E}_{c}=106 \times 10^{-5}$ (more than eight times).

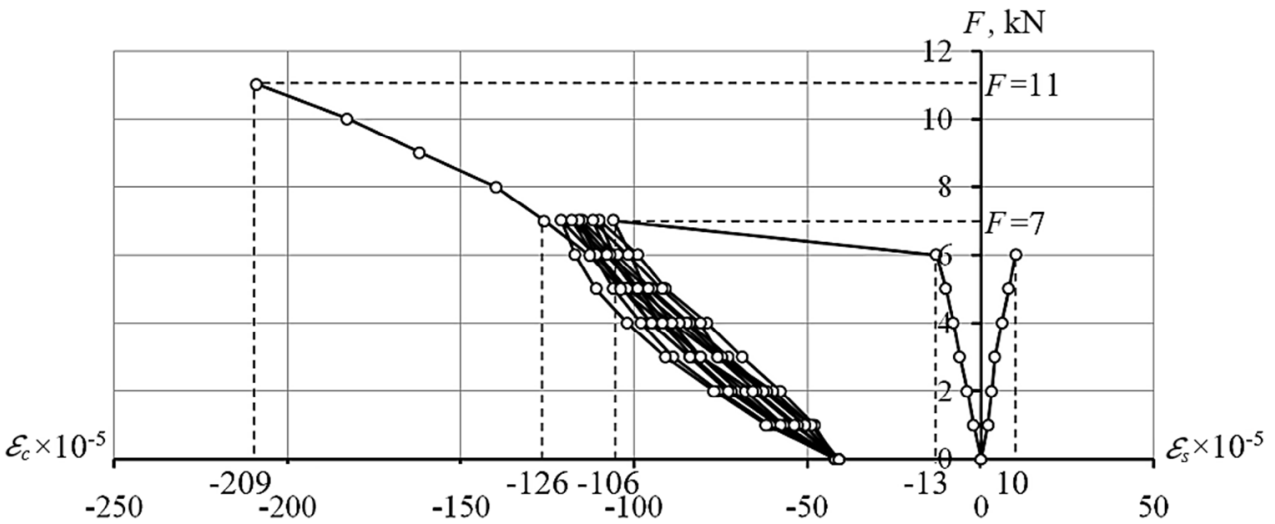

Fig. 14. Deformation diagram of compressed $\left(\mathcal{E}_{c}\right)$ and stretched $\left(\mathcal{E}_{s}\right)$ reinforced concrete under the action of repeated loads at $\mathrm{RCg}-1-3$.

At the 1st cycle of loading, the values of the full and residual strain of concrete in compression zones were: $\mathcal{E}_{c, \max }=6 \times 10^{-5}$ and $\mathcal{E}_{c, p l}=42 \times 10^{-5}$. Over the next 9 cycles before the 10 th inclusively, in the areas of compression was moderate growth of total deformation to $\mathcal{E}_{c, \max }=126 \times 10^{-5}$. Residual deformation is almost not increased and at the 10 th cycle was $\mathcal{E}_{c, p l}=42 \times 10^{-5}$. On the next 11 th destructive cycle, due to increasing the load above the level $\eta=0.6$ occurred an increase of total deformation to $\mathcal{E}_{c, \max }=209 \times 10^{-5}($ at $F=11 \mathrm{kN})$.

Deformation of SFRC samples SFRCg-1-3 (unlike strains in the same samples of RCg1-3) was fully tracked during all cycles (Fig. 15), as in the zones of compression and tensile zones - the process of fracturing has not led to failure of the strain gauges, which were placed in the tensile zones.

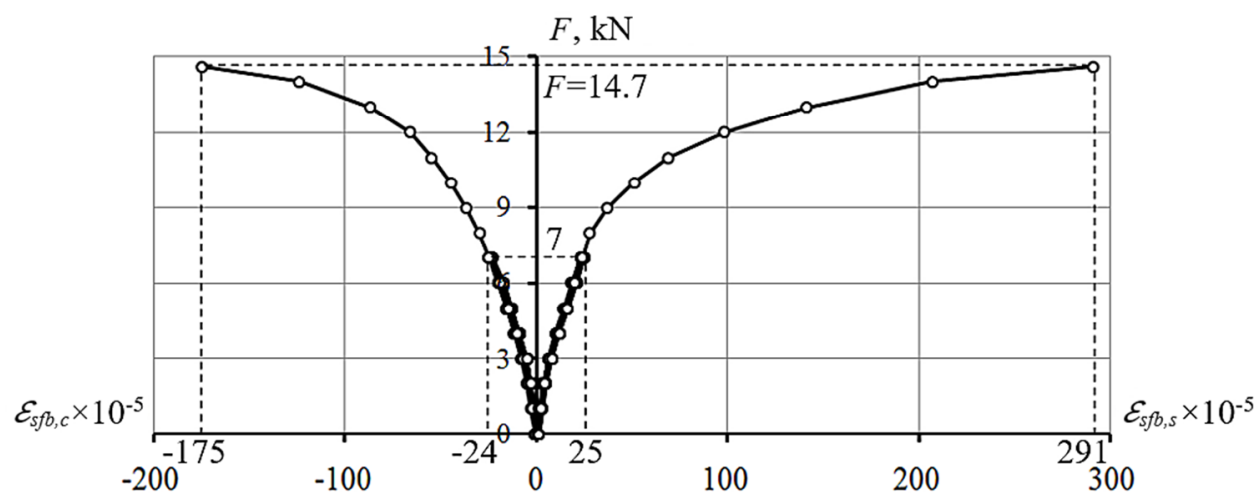

Fig. 15. Deformation diagram of compressed $\left(\mathcal{E}_{s f b, c}\right)$ and stretched $\left(\mathcal{E}_{s f b, s}\right)$ SFRC under the action of repeated loads at SFRCg-1-3. 


\section{Conclusions}

On the basis of conducted research, it can be argued that drainage gutters and non-pressure pipes made of SFRC under repeated loads have a high hardness and crack resistance in comparison with similar items which is made of ordinary reinforced concrete.

At the repeated loads in SFRC gutters for 10 times loading deformation of the crosssections were (at maximum load cycle) $\Delta l=0.47 \div 0.98 \mathrm{~mm}$, while at typical RC elements these values were (from the 1 st to the 10 th cycle) is several times greater $\Delta l=2.59 \div 2.78 \mathrm{~mm}$.

At the repeated loads in SFRC pipes for 10 times of horizontal load $\left(\Delta l_{h}\right)$ and vertical $\left(\Delta l_{v}\right)$ movement diametrical of the cross sections did not change and was at a maximum load cycle of $0.12 \div 0.14 \mathrm{~mm}$, while in typical RC elements, these values constantly (from the 1 st to the 10 th cycle) was increased $\Delta l_{h}=5.16 \div 6.41 \mathrm{~mm}$ and $\Delta l_{v}=4.49 \div 4.64 \mathrm{~mm}$, respectively. In addition to the increments of load $(\triangle F=1 \mathrm{kN})$ average moving sections in SFRC samples was $0.01 \div 0.02 \mathrm{~mm}$, and $\mathrm{RC}-0.1 \div 0.3 \mathrm{~mm}$. At repeated loads, which ranged $\eta_{c y c}=0.6$ of the destructive, during 10 times the load in the pipes from the SFRC full and permanent deformation virtually did not change, while in RC samples they increased by $10 \div 25 \%$.

At the repeated loads, level of which does not exceed $70 \%$ of the destructive, SFRC pipes works elastic - moving in diametrically opposite directions do not exceed $0.05 \%$ of the diameter, and the cracks occurs only when uses additional loading.

Cracks in the experimental gutters and pipes of reinforced concrete occurred at the 1 st cycle but in the samples from SFRC only on the 11th. The first visible cracks in the samples from SFRC in most cases were grown at one or two steps of the load from destructive forces, and in the samples of reinforced concrete at loads equal to 0.3-0.4 of maximum carrying capacity of the section. They were recorded in all samples only in the zone with maximum bending moment.

In a typical reinforced concrete elements cracks were almost straight, with a clear gaps, and in SFRC samples, the cracks were with fuzzy contours and expressed netting.

\section{References}

1. L. Dvorkin, O. Dvorkin, Y. Ribakov. A method for optimal design of steel fiber reinforced concrete composition. Materials and Design, Elsevier (2011)

2. R. Kinash, V. Bilozir. Deformational calculation method of bearing capability of fiberconcrete steel bending elements. Czasopismo Techniczne (2015)

3. K.V. Talantova. Stroytelnye konstruktsyy s zadannymy svoistvamy na osnove stalefybrobetona. Barnaul, Russia (2009)

4. Y.M. Babych, O.V. Andriichuk. Resursoekonomni materialy, konstruktsii, budivli ta sporudy, Rivne, 18, 119-126 (2009)

5. O.V. Andriichuk, I.M. Yasyuk. Naukovi notatky, Lutsk, 45, 7-14 (2014)

6. O.V. Andriichuk, Y.M. Babych. Stalefibrobetonni beznapirni truby. Lutsk, Ukraine (2012)

7. Y.M. Babych, O.V. Andriichuk. Proektuvannia ta vyhotovlennia beznapirnykh trub iz stalefibrobetonu. Lutsk, Ukraine (2012)

8. O.V. Andriichuk, I.M. Yasyuk. Resursoekonomni materialy, konstruktsii, budivli ta sporudy, Rivne, 18, 371-378, (2015)

9. Y.M. Babych, O.V. Andriichuk. Fizyko-khimichna mekhanika materialiv, 4, 59-62 (2016)

10. O.V. Andriichuk, I.M. Yasyuk. Resursoekonomni materialy, konstruktsii, budivli ta sporudy, 30, 86-95 (2015) 